\title{
Tekstil Kompozitlerinin Elektromanyetik Kalkanlama Testlerinin Yapılmasında Kullanılmak Üzere Ekonomik Bir Kutu-Test Düzeneğinin Geliştirilmesi
}

\author{
Devrim Demiray Soyaslan ${ }^{1 *}$ \\ ${ }^{1}$ Burdur Mehmet Akif Ersoy Üniversitesi, Mühendislik-Mimarlık Fakültesi, Polimer Mühendisliği Bölümü, Burdur, Türkiye, (ORCID: 0000-0000-0000-0000)
}

(İlk Geliş Tarihi 13 Kasım 2019 ve Kabul Tarihi 7 Aralık 2019)

(DOI: 10.31590 /ejosat.646344)

ATIF/REFERENCE: Soyaslan, D. D. (2019). Tekstil Kompozitlerinin Elektromanyetik Kalkanlama Testlerinin Yapılmasında Kullanılmak Üzere Ekonomik Bir Kutu-Test Düzeneğinin Geliştirilmesi. Avrupa Bilim ve Teknoloji Dergisi, (17), 852-859.

\begin{abstract}
Öz
Son yıllarda iletken tekstil ve kompozitleri, elektromanyetik girişimlerin gücünü zayıflatmak için yaygın olarak kullanılmaya başlanmıştır. Bu malzemelerin, elektromanyetik koruyucu olarak fonksiyonellikleri, ekranlama etkinliklerinin (shielding effectiveness) doğrudan ölçümü ile değerlendirilmektedir. Günümüzde; elektromanyetik koruyucu malzemenin boyutuna ve ölçülen frekans aralığına bağlı olarak çeşitli test yöntemleri kullanılmaktadır. Bu test yöntemlerinin pek çoğu, ölçüm esnasında büyük numune boyutları gerektirmesi ve çok maliyetli olmalarından dolayı fonksiyonel olarak kabul edilmemektedir. Bu nedenle hala, küçük numuneler kullanılarak ölçüm yapabilecek, pratik ve ekonomik olan bir test yönteminin geliştirilmesine ihtiyaç duyulmaktadır. Bu çalışmada; korunmalı kafes metodu (Shielded box (enclosure) method) kullanılarak tasarlanmış bir test düzeneğinin tasarım, yapım ve ölçüm prensibi anlatılmaktadır. Korunmalı kafes metodunda tasarlanan kafeslerin halen bir standardının olmaması da, bu konunun hala gelişmeye ve yeniliklere açık olduğunu ortaya koymaktadır. Bu durum, çalışmada korunmalı kafes metoduna göre yeni bir test yöntemi tasarlanması yönündeki motivasyonu oluşturmuştur. Tasarlanan düzenekte testlerin gerçekleştirilebilmesi amacı ile numune olarak karbon elyaf ve karbon partikül katkılı epoksi kompozitler kullanılmıştır. Böylece çalışmada, farklı karışım oranlarına sahip dört adet numune ile çalışılmıştır. Tasarlanan kutu test düzeneğinin güvenilirliğinin belirlenmesi için, söz konusu düzenekten elde edilen sonuçlar, eş eksenli iletim hattı (coaxial transmission line method based on ASTM D 4935-10) yöntemi ile elde edilen sonuçlarla karşılaştırılmıştır. Eş eksenli iletim hattı kullanılarak yapılan testler ise YorkEMC laboratuarlarında gerçekleştirilmiştir. Her iki test yöntemi ile yapılan testler sonucunda, bu çalışmada tasarlanan ve üretilen kutu test düzeneğinden alınan sonuçların eş eksenli iletim hattı yönteminden elde edilen sonuçlarla neredeyse çok yakın olduğu ve aralarında belirgin bir fark olmadığı yargısına varılmıştır. Son olarak da; bu çalışmada önerilen yöntemin tekstil ve kompozit yapıların elektromanyetik koruma değerlerinin belirlenmesinde kullanılmak üzere umut verici olduğu sonucuna varılmıştır.
\end{abstract}

Anahtar Kelimeler: Karbon, Elyaf, Kompozit, Elektromanyetik, Düzenek

\section{Development of an Economical Box Setup for the Use of Electromagnetic Shielding Tests of Textile Composites}

\begin{abstract}
* Sorumlu Yazar: Xxxx Üniversitesi, Xxxx Fakültesi, Xxxx Bölümü, İstanbul, Türkiye, ORCID: 0000-0000-0000-0000, xxxx@,xxx.xx.xx
\end{abstract}


In recent years, conductive textiles and composites have been widely used to weaken the power of electromagnetic interference. The functionality of these materials as electromagnetic shielding is evaluated by direct measurement of shielding effectiveness. Today; various test methods are used depending on the size of the electromagnetic shielding material and the measured frequency range. Many of these test methods are not considered functional because they require large sample sizes during measurement and are very costly. Therefore, there is still a need for the development of a practical and economical test method that can be measured using small samples. In this study; the design, construction and measurement principle of a test setup designed using a shielded box (enclosure) method is described. The fact that the boxes designed in the shielded box method does not yet have a standard reveals that this issue is still open to development and innovation. This was the motivation for designing a new test method according to the shielded box method. In order to determine the reliability of the designed box test setup, the results obtained from this setup were compared with those obtained by coaxial transmission line method based on ASTM D 4935-10. As a result of this comparison, the proposed method is promising for textile and composite structures.

(Minimum 250 - Maximum of 400 words and content should be written in a way to include material, method, findings and results.)

Keywords: Carbon, Fiber, Composite, Elektromanyetik, Setup

\section{Giriş}

Son yıllarda elektromanyetik (EMI) koruyucu malzemelerin; mikrodalga fırın, mobil telekomünikasyon, Wi-Fi, radar ve benzeri tüm radyasyon kaynaklarından canlı organizmaların korunmasında ve bu kaynakların neden olduğu girişimlerden devrelerdeki hassas bileşenleri ve parçaları korumak amacıyla, oldukça dikkat çektikleri bilinmektedir (Yang, Gupta, Dubley, \& Lawrence, 2005); (Micheli, Vricella, Pastore, \& Marchetti, 2014); (Neo \& Varadan, 2004)[1-3]. Bu malzemeler içerisinde, metal bazlı ve polimer bazlı malzemelerin en yaygın kullanılan iki EMI koruyucu malzeme türü oldukları belirtilmektedir (Thomassin, vd., 2013; Han vd., 2001; Jayalakshmi vd., 2019; Chung, 2001; Huang vd., 2007; Al-saleh ve Sundararaj, 2009; Gupta ve Tai, 2019).

Metaller veya metal kaplı materyaller, 40-100 dB arasında elektromanyetik korumaya sahiptirler. Yine de bu materyaller elektromanyetik dalga emici olarak kullanılamazlar. Emilim yoluyla elektromanyetik koruma, deri kalınlığının artmasına bağlı olarak artırılabilir ki bu da materyalin elektriksel iletkenliğinin değiştirilmesiyle sağlanabilir (Kim vd., 2002). Bununla birlikte, metal bazlı malzemeler yüksek sicaklıklarda yüksek yoğunluklu ve düşük mekanik özelliklere sahiptir ve polimer bazlı malzemeler yüksek sıcaklıktaki ortamlarda kullanılamaz. Bu durumda, sadece mükemmel termal mekanik özelliklere sahip değil, aynı zamanda EMI ekranlama özelliklerine sahip yapısal ve işlevsel bir malzemeye ihtiyaç duyulmaktadır. Son yıllarda metalik korumaların yerini, dikkate değer esneklik ve hafiflik özelliklerinden dolayı elyaf dolgulu plastikler, kaplama plastikler, iletken laminantlar, çeşitli kompozitler ve çeşitli tipte iletken kumaşlar almaktadır (Safarova vd., 2016; Chen vd., 2015; Stefan vd., 2009; Volski ve Vandenbosch, 2009). Artık bu karmaşık, homojen olmayan ve gözenekli materyallerin de koruma davranışlarının tahminlenmesi yapılabilmektedir (Liu vd., 2014; Lopez vd., 2013). Özellikle karbon elyaf ve karbon partikül dolgulu kompozitler ve bu malzemelerin elektromanyetik koruma etkinliklerinin belirlenmesi çok çalışılan konulardan biri olmuştur. Yapılan çok sayıda çalışma incelendiğinde, bu malzemelerin elektromanyetik koruma etkinliklerinin tespitinin aşağıda belirtilen denklemler esas alınarak yapıldığı tespit edilmiştir (Munalli vd., 2019).

Gelen güç (İncident power) bilindiğinde, iki bağlantı noktasında yansıtılan ve iletilen gücü ölçmek için bir koaksiyel veya dikdörtgen dalga kılavuzu numune tutucusu boyunca bağlanmış iki portlu bir vektör ağ analizörü kullanılabilir. Pi olarak adlandırılan gelen güç; üç gücün toplamı olarak tanımlanabilir (Denklem 1). Birincisi, hava / kompozit sınırında birinci uca yansıyan güç (Pr ), ikincisi, soğurulan güç (Pa ), ve üçüncüsü de, ikinci sınır olan kompozit / hava sınırından sonra iletilen güçtür (Pt ).

$$
\mathrm{Pi}=\mathrm{Pr}+\mathrm{Pa}+\mathrm{Pt}
$$

\footnotetext{
Pi : Gelen güç (İncident power)

Pr : Yansıyan güç (Reflected power)

$\mathrm{Pt}$ : İletilen güç (Transmitted power)

$\mathrm{Pa}$ : Soğurulan güç (Absorbed power)
}

Güç dengesi göz önüne alındığında; malzemenin ekranlama etkinliği değeri (SE), yansıma yoluyla ekranlama toplamı ile soğurma yoluyla ekranlamanın toplamı olarak verilir ki bu da, aşağıdaki denklemle tanımlanır (Denklem 2).

$\mathrm{SE}=10 \log 10(\mathrm{Pi} / \mathrm{Pt})$

Bir malzemenin elektromanyetik koruma etkinliğini belirlemeye yönelik olarak günümüzde en sık kullanılan metotlar şunlardır (Jagatheesan vd., 2015; Geetha vd., 2009).

Eş eksenli iletim hattı (Coaxial transmission line method)

Korunmalı oda metodu (Shielded room method)

Açık alan metodu (Open field or Free space method) 
Korunmalı kafes metodu (Shielded box (enclosure) method)

Yukarıda belirtilen her metodun avantaj ve dezavantajları bulunmaktadır. Bu çalışmada korunmalı kafes metodu (Shielded box (enclosure) method) baz alınarak geliştirilmiş bir test düzeneği tasarlanmıştır. Tasarlanan bu test düzeneği kullanılarak korunmalı kafes metoduna göre yapılan ölçümler ile ASTM D 4935-89 standardını temel alan NBS Eş eksenli iletim hattı metoduna (NBS Flanged Coaxial Transmission Line Test Fixture) göre yapılan ölçümler karşılaş̧ırılmıştır.

\section{Materyal ve Metot}

\subsection{Korunmalı Kafes Metoduna Göre Kutu Test Düzeneğinin Tasarlanması}

Çalışmada tasarlanan düzenek; ahşap kontraplak malzeme kullanılarak dikdörtgenler prizması şeklinde tasarlanmış ve Şekil.1'de gösterildiği üzere boyutlandırılmıştır. Düzeneğin iç duvarları; $10 \mathrm{MHz}-9000 \mathrm{MHz}$ aralığında $100 \mathrm{~dB}$ koruma etkinliğine sahip tamamen geçirimsiz, 1 mm kalınlıkta bakır metal bir plaka ile kaplanmıştır. Söz konusu bakır plaka, elektromanyetik koruma uygulamaları için çeşitli malzemeler üreten HollandShielding firmasından temin edilmiş olup elektromanyetik kalkanlama amaciyla piyasada kullanılan bir malzemedir. Söz konusu düzenekte bakır metal plaka kullanılmasının sebebi, ölçümler esnasında dışarıda oluşabilecek elektromanyetik girişimlerin içeride bulunan alıcı ve verici sistemlere ulaşarak veri alışverişini etkilememesi içindir. Düzenek 50x50x100 cm ebatlarında olup eşit boyutlara sahip iki ayrı odacığa sahiptir. Odalardan birisi sinyal verici aparatın (Seeed Studio marka el tipi sinyal jeneratörü (RF Handheld Signal Generator)) yerleştirildiği, diğeri ise sinyal alıcı aparatın (Seeed Studio marka el tipi spektrum analizör (RF Handheld Spectrum Analyzer)) yerleştirildiği odadır. Odalardan birinin üst kapağı takılıp çıkarılabilir olarak tasarlanmıştır. Düzeneğin tam ortasında, iki odayı birbirinden ayıran ve aynı zamanda numunenin yerleştirildiği portatif, takılıp çıkarılabilen bir paravan bulunmaktadır. Bu paravanın ortasına $30 \times 30 \mathrm{~cm}$ boyutlarında numunenin yerleştirileceği bir pencere açılmıştır. Paravan yüzeyinin geri kalan kısmı ise çift yönlü olarak yine bakır metal plaka ile (ölçümler esnasında elektromanyetik dalgaların bir odadan diğerine geçişini engellemek amacıyla) kaplanmıştır (Şekil 2). Ölçüm kutusuna ait dış görünüş Şekil 3 'de verilmiştir.

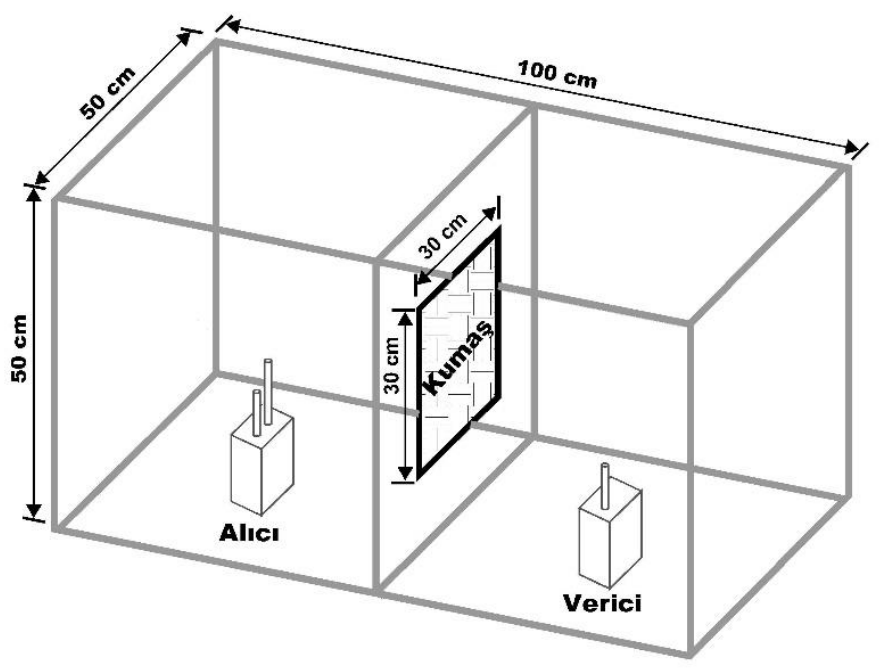

Şekil.1. Elektromanyetik koruma etkinliği ölçüm kutusuna ait şematik çizim
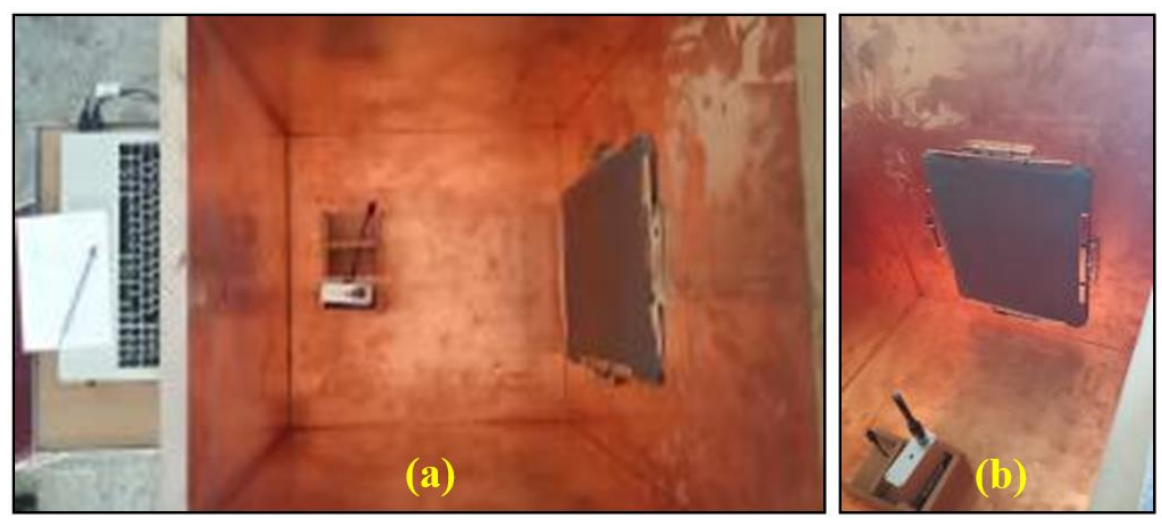

Şekil 2.(a) Elektromanyetik koruma etkinliği ölçüm kutusu (baktr plaka ile kaplanmış bir odanın üstten iç görünüşü ve ortada bulunan pencereye numune yerleştirilmiş hali), (b) Numunenin pencereye sabitlenmesi ve el tipi sinyal jeneratörü ve el tipi spektrum analizör cihazlarınin odaciklara konumlandirlması 


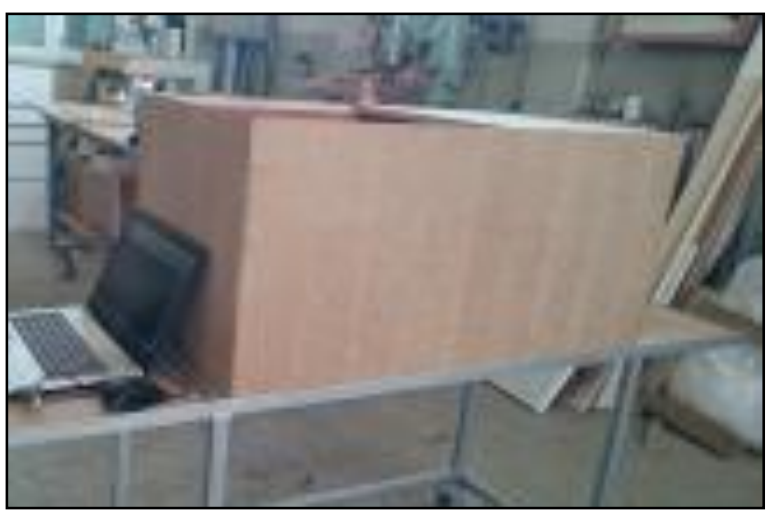

Şekil 3. Dikdörgenler prizması şeklinde tasarlanmış Elektromanyetik koruma etkinliği ölçüm kutusunun dış görünüşü

Ölçümü yapılmak istenen numune, paravanda bulunan pencereye sabitlenmiş (Şekil 2) ve bir adet el tipi sinyal jeneratörü bir odaya ve bir adet el tipi spektrum analizör de diğer odaya konumlandırılarak bilgisayar aracılığı ile veriler kontrol altına alınarak ve elektromanyetik koruma etkinliği testleri gerçekleştirilmiştir (Şekil 4).

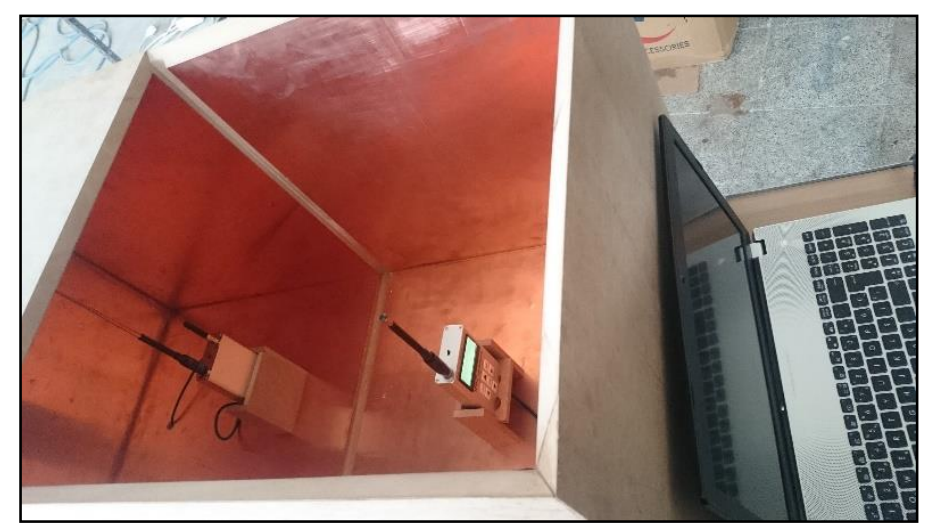

Şekil.4. El tipi sinyal jenaratörü ve el tipi spektrum analizör aparatların ölçüm kutusunun iki ucundaki odacıklara konumlandırllması ve verilerin bilgisayar aracılı̆̆lyla işlenmesi

Tasarımı yapılan test düzeneğinin ölçümlerinin, standartlara uygun bir başka test cihazının ölçümleriyle kıyaslanması ile ilgili olarak da, ASTM D 4935-89 standardını temel alan NBS test düzeneği (NBS Flanged Coaxial Test Fixture) seçilmiştir. NBS test düzeneğinin (Şekil 5) seçilmiş olmasının nedeni, benzer prensibe göre tasarlanan diğer bazı düzeneklerden farklı olarak (ASTM ES- 7 Coaxial Transmission Line Fixture), bu test düzeneğinde elektriksel kontak probleminin elimine edilmiş olmasıdır. Bu nedenle bu düzenek, yüzeyi kısmen veya tamamen izole edilmiş materyallerin elektromanyetik koruma performans testleri için daha uygun görülmektedir. Çalışmada araştırma yapılacak olan epoksi kompozit numunelerinin yüzeylerinin kısmen izole olmaları, bu materyallerin ekranlama verimliliği testlerinin yapılmasında NBS test düzeneğinin seçilmesinin en önemli nedenidir.

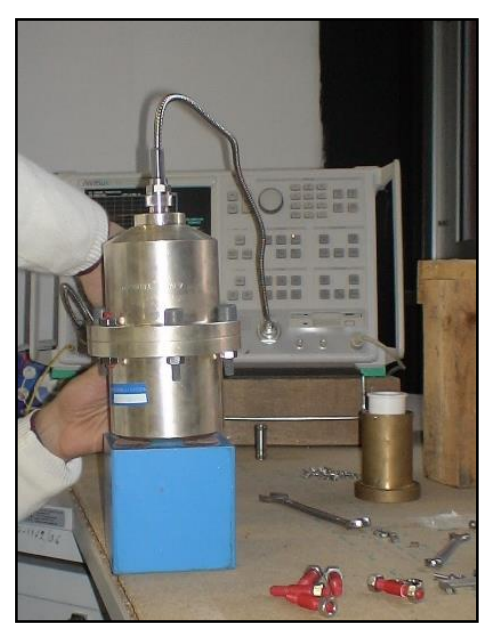

Şekil 5. ASTM D 4935-89 standardına göre geliştirilmiş NBS test düzeneğ $i$ 


\subsection{Test Ölçümleri İçin Kullanılan Numunelerin Özellikleri}

Çalışmada, dört farklı numune kullanılmıştır. Numuneler; epoksi matriks içerisine karbon elyaf ve/veya karbon partikül ilave edilmiş kompozit numunelerdir. Numunelerin üretimi; epoksi içerisine karbon elyaf ve/veya karbon partiküllerinin mekanik mikserde karıştırıldıktan sonra, elle kalıplara dökülmesiyle gerçekleştirilmiştir. Numunelere ait özellikler aşağıda Tablo 1'de verilmiştir.

Tablo 1. Numunelere ait özellikler

\begin{tabular}{c|c|c|c|c}
\hline $\begin{array}{c}\text { Numune } \\
\text { kodu }\end{array}$ & $\begin{array}{c}\text { Kalınlık } \\
\mathbf{( m m )}\end{array}$ & $\begin{array}{c}\text { Yoğunluk } \\
\mathbf{( g / c m 2})\end{array}$ & $\begin{array}{c}\text { 100g epoksi içerisinde bulunan } \\
\text { karbon elyaf miktarı (g) }\end{array}$ & $\begin{array}{c}\text { 100g epoksi içerisinde bulunan } \\
\text { karbon partikül miktarı (g) }\end{array}$ \\
\hline$N 1$ & 3,9 & 0,455 & - & - \\
\hline$N 2$ & 7,4 & 1,4 & 1 & - \\
\hline$N 3$ & 2,8 & 0,5 & 0,5 & 0,5 \\
\hline$N 4$ & 3,76 & 0,612 & - & 1 \\
\hline
\end{tabular}

\section{Araştırma Sonuçları ve Tartışma}

Elde edilen numuneler önce çalışma kapsamında tasarlanan ölçüm kutusunda ölçümlere tabi tutulmuş, ardından Eş eksenli iletim hattı (Coaxial transmission line method) test düzeneğinde ölçülmüşlerdir. Aşağıda Tablo 2'de 'Ölçüm kutusu'ndan elde edilen elektromanyetik koruma etkinliği değerleri verilmiş olup, Tablo.3'de ise 'Eş eksenli iletim hattı (Coaxial transmission line method) test düzeneği'nde elde edilen koruma etkinliği değerleri verilmiştir. Şekil 6, Şekil 7, Şekil 8 ve Şekil 9'da, her iki ölçüm düzeneğinden elde edilen değerlerin numuneler bazında ayrı ayrı karşılaştırılması grafiksel olarak verilmiştir. Bu grafiklerde, kırmızı renk ile gösterilen değerler 'Ölçüm kutusu'ndan elde edilen elektromanyetik koruma etkinliği değerlerini temsil ederken, yeşil renk ile gösterilen değerler 'Eş eksenli iletim hattı (Coaxial transmission line method) test düzeneği'nde elde edilen koruma etkinliği değerlerini temsil etmektedir. Grafiklerden de görüldüğü üzere, her dört numune tipinde de iki ölçüm düzeneğinden elden değerler birbirleri ile uyumludur ve çok yakın değerler elde edilmiştir.

Tablo 2. Ölçüm kutusundan elde edilen elektromanyetik koruma etkinliği değerleri

\begin{tabular}{l|c|c|c|c|c|c|c|c|c|c|c|c}
\hline Frekans (MHz) & 27 & 50 & 100 & 250 & 500 & 900 & 1000 & 1800 & 2400 & 2600 & 5000 & 6000 \\
\hline$N 1$ & -37 & -43 & -31 & -21 & -34 & -62 & -72 & -25 & -21 & -31 & -48.5 & -43 \\
\hline$N 2$ & -37 & -43 & -32 & -22 & -41.5 & -80 & -83 & -45 & -63 & -47 & -90 & -60 \\
\hline$N 3$ & -37.5 & -44 & -32 & -22 & -44 & -83 & -85 & -48 & -44 & -44 & -75 & -60.5 \\
\hline$N 4$ & -37.5 & -43 & -32 & -21 & -32.5 & -62 & -72 & -24 & -26 & -32 & -54 & -54 \\
\hline
\end{tabular}

Tablo 3. Eş eksenli iletim hattı (Coaxial transmission line method) kullanılarak elde edilen ölçüm sonuçları

\begin{tabular}{l|c|c|c|c|c|c|c|c|c|c|c|c}
\hline $\begin{array}{c}\text { Frekans } \\
\text { (MHz) }\end{array}$ & 27 & 50 & 100 & 250 & 500 & 900 & 1000 & 1800 & 2400 & 2600 & 5000 & 6000 \\
\hline$N 1$ & $-36,8$ & -42.4 & -30.7 & -20.9 & -33.4 & -62.3 & -71.8 & -23 & -19.8 & -30.9 & -47.5 & -42.2 \\
\hline$N 2$ & -36 & -42.6 & -31.8 & -21.4 & -40.9 & -79.9 & -82.1 & -44.6 & -62.7 & -46.9 & -90.2 & -60.1 \\
\hline$N 3$ & -37.2 & -43.7 & -32.4 & -21.3 & -43.9 & -82.7 & -85.1 & -46.4 & -43.2 & -43.7 & -76 & -59.7 \\
\hline$N 4$ & -37.1 & -43.1 & -30.9 & -20.7 & -32.3 & -61.1 & -72.0 & -23.6 & -26.4 & -31.7 & -53.9 & -53.8 \\
\hline
\end{tabular}


European Journal of Science and Technology

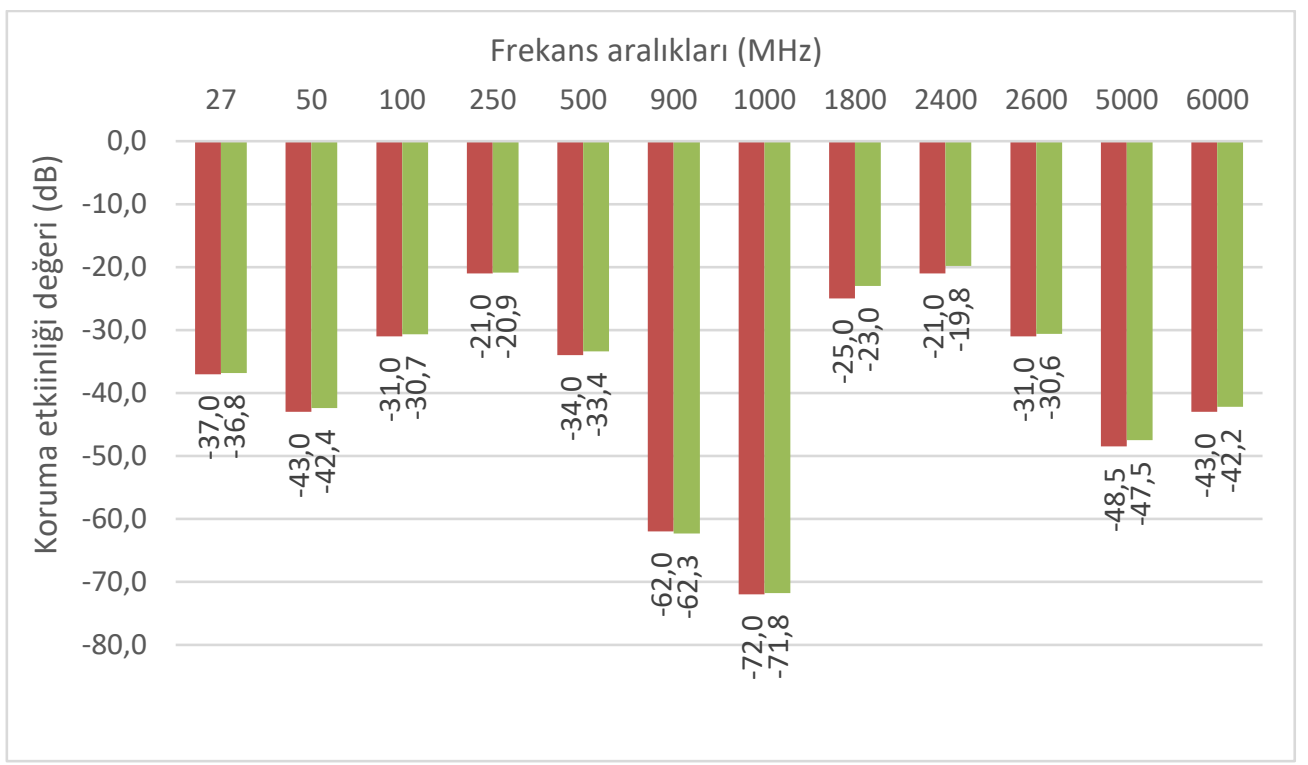

Şekil 6. N1 numunesinin, ölçüm kutusu ve eş eksenli iletim hattı düzenekleri kullanılarak elde edilen ölçüm sonuçları

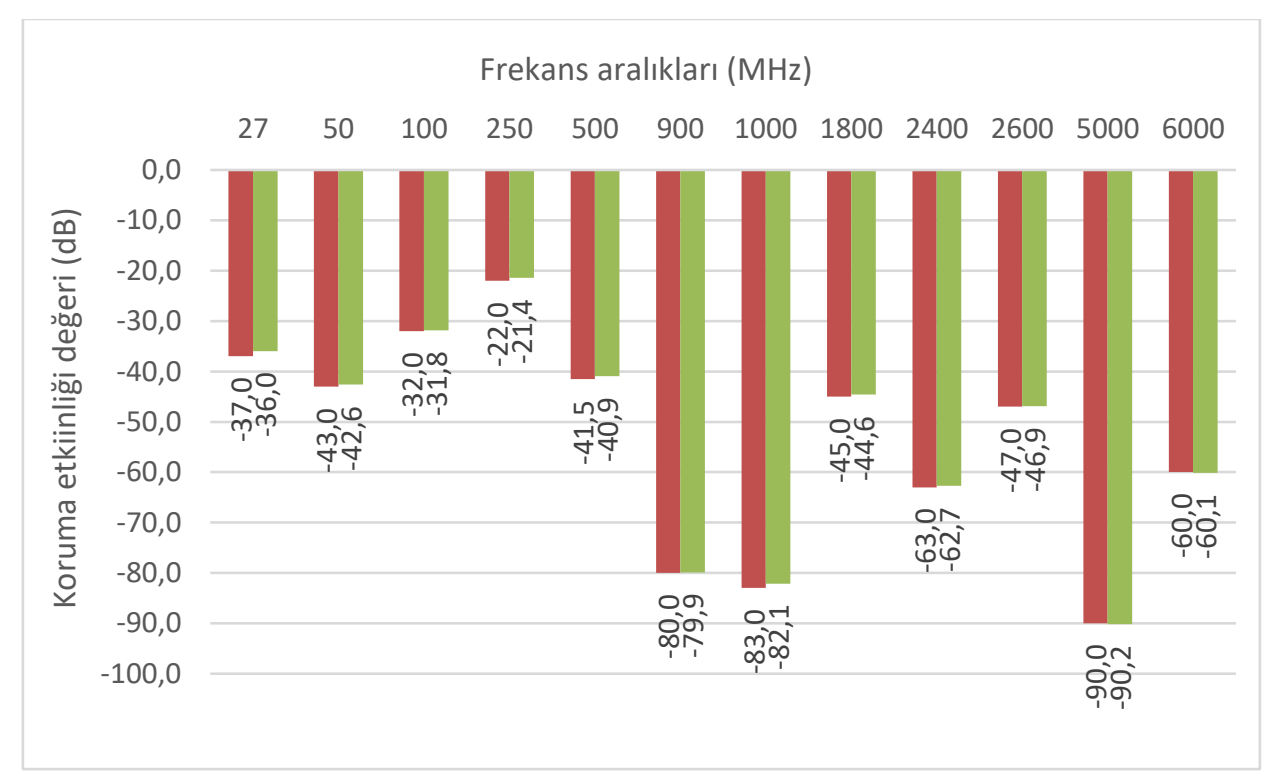

Şekil 7. N2 numunesinin, ölçüm kutusu ve eş eksenli iletim hattı düzenekleri kullanılarak elde edilen ölçüm sonuçları 


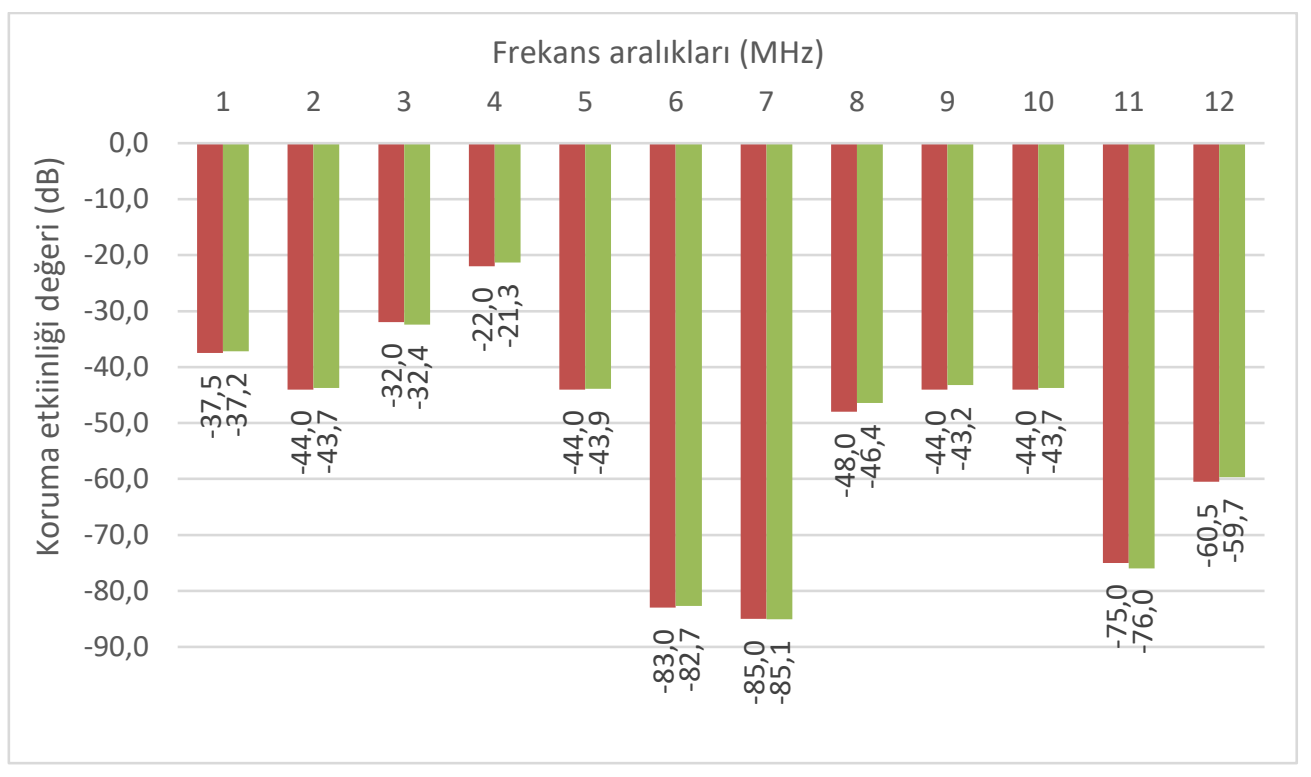

Şekil 8. N3 numunesinin, ölçüm kutusu ve eş eksenli iletim hattı düzenekleri kullanılarak elde edilen ölçüm sonuçları

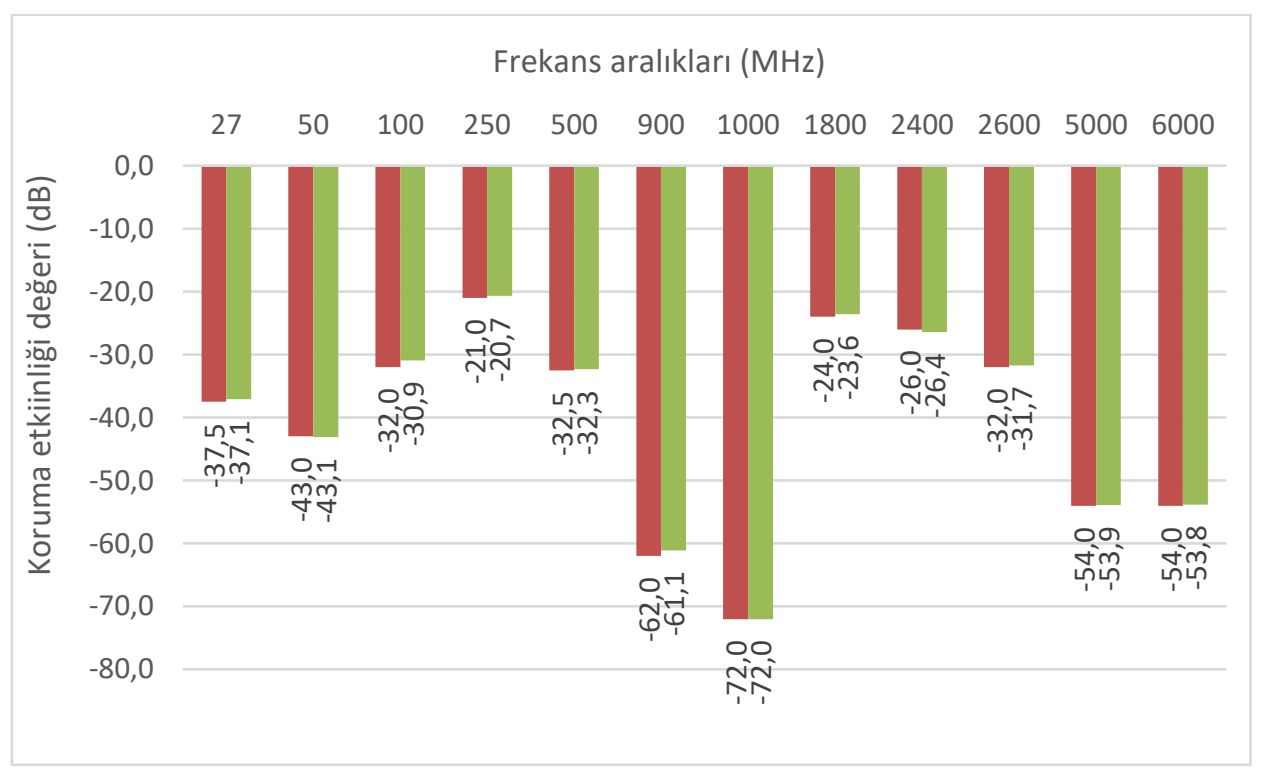

Şekil 9. N4 numunesinin, ölçüm kutusu ve eş eksenli iletim hattı düzenekleri kullanılarak elde edilen ölçüm sonuçları

\section{Sonuç}

Çalışmada, karbon elyaf ve carbon partikül destekli epoksi kompozitlerin elektromanyetik koruma performanslarının belirlenmesi amacıyla "Korunmalı kafes metodu (Shielded box (enclosure) method" esasına göre bir test kutusu tasarlanmış ve üretilmiştir. Test kutusu, 50x50x100 cm ebatlarında tamamen geçirimsiz olacak şekilde tasarlanmış ve bu amaçla kutu iç duvarları elektromanyetik yalıtım özelliğine sahip bakır metal levha ile kaplanmış ve sızdırma ihtimali olan bölgeler için de tampon aksesuarlar kullanılmıştır. Ölçümler için el tipi sinyal jeneratörü ve spektrum analizör kullanılmıştır. Kutu test düzeneğinde yapılan ölçümlerin karşılaştırılabilmesi için numuneler ayrıca York EMC Laboratuvarlarında bulunan "Eş eksenli iletim hattı (Coaxial transmission line method)" test düzeneğinde ölçülmüşlerdir. Her iki test düzeneğinden elde edilen sonuçların birbirleriyle uyumlu oldukları, aralarında kayda değer bir sapma olmadığı belirlenmiştir.

Çalışmada tasarlanan kutu test düzeneği; oldukça ekonomik, kullanıcı dostu ve açık alan ölçümlerine kıyasla nispeten daha küçük numune boyutu gerektirmesi gibi nedenlerden dolayı avantajlı ve uygulanabilir olarak nitelendirilmiştir. Çalışma sayesinde "Korunmalı kafes metodu" esasına göre bir düzenek geliştirilmiş olup ülkemiz bilim insanlarına bu alanda daha hızlı ve daha ekonomik çalışma firsatı tanınmış ve dışa bağımlılık belirli bir oranda azaltılmıştır. 
"'Eş eksenli iletim hattı (Coaxial transmission line method)" test düzeneği ile yapılan ölçümler ile karşılaştırma sonucunda, "'Korunmalı kafes metodu” esasına göre geliştirilen düzeneğin orta düzeyde elektrik iletkenliğine sahip tekstil ve kompozit yapıları için umut verici olduğu sonucuna varılmıştır. İlerleyen çalışmalarda kutu test düzeneğinin geliştirilmesi üzerinde daha işbirlikçi çalışmalar yapılması planlanmaktadır.

\section{Kaynakça}

Al-saleh, M. H., \& Sundararaj, U. (2009). Electromagnetic interference shielding mecha-nisms of CNT/polymer composites,. Carbon, 47(7), 1738-1746.

Chen, L., Yin, X., Fan, X., Chen, M., Ma, X., Cheng, L., \& Zhang, L. (2015). Mechanical and electromagnetic shielding properties of carbon reinforced silicon crbide matrix composites. Carbon(95), 10-19.

Chung, D. D. (2001). Electromagnetic interference shielding effectiveness of carbon materials. Carbon, 39(2), $279-285$.

Geetha, S., Satheesh Kumar, K. K., Rao, C. R., Vajiyan, M., \& Trivedi, D. C. (2009). EMI shielding methods and materials -Areview, , 2009, 112, 2079-2086. Journal of Applied Polymer Science(112), 2079-2086.

Gupta, S., \& Tai, N. H. (2019). Carbon materials and their composites for electromagnetic interference shielding effectiveness in Xband. Carbon, 152, 159-187.

Han, E. G., Kim, E. A., \& Oh, K. W. (2001). Electromagnetic interference shielding effec-tiveness of electroless Cu-plated PET fabrics. Synthetic Metals, 123(3), 469-476.

Huang, Y., Li, N., Ma, Y., Du, F., Li, F., He, X., . . Chen, Y. (2007). interference shielding efficiency of its epoxy composites. Carbon, 45(8), 1614-1621.

Jagatheesan, K., Ramasamy, A., Das, A., \& Basu, A. (2015). Fabrics and their composites for electromagnetic applications. Textile progress, $47(2), 87-161$.

Jayalakshmi, C. G., Inamdar, A., Anand, A., \& Kandasubramanian, B. (2019). Polymer matrix composites as broadband radar absorbing structures for stealth aircrafts. Journal of Applied Polymer Science, Article number: 47241, 136(14), 1-21.

Kim, M. S., Kim, H. K., Byun, S. W., Jeong, S. H., Joo, J. S., Song, K. T., . . Lee, J. Y. (2002). PET fabric/polypyrrole composite with high electrical conductivity for EMI shielding. Synthetic Metals, 123(2-3), 233-239.

Liu, Z., Yang, Y., Wang, X. C., \& Zhou, Z. (2014). Prediction model of shielding effectiveness of electromagnetic shielding fabric with rectangular hole. Progress In Electromagnetics Research C(48), 151-157. doi:10.2528/PIERC14022103

Lopez, A., Vojtech, L., \& Neruda, M. (2013). Comparison Among Models to Estimate the Shielding Effectiveness Applied to Conductive Textiles. Advances in Electrical and Electronic Engineering,(11), 387-391.

Micheli, D., Vricella, A., Pastore, R., \& Marchetti, M. (2014). Synthesis and electromagnetic characterization of frequency selective radar absorbing materials using carbon nanopowders. Carbon(77), 756-774.

Munalli, D., Dimitrakis, G., Chronopoulos, D., Greedy, S., \& Long, A. (2019). Electromagnetic shielding effectiveness of carbon fibre reinforced composites. Composites Part B: Engineering, 173(15), 1-12.

Neo, C. P., \& Varadan, V. K. (2004). Optimization of carbon fiber composite for microwave absorber. IEEE Transactions on Electromagnetic Compatibility, 46(1), 102-106.

Safarova, V., Tunak, M., Truhlar, M., \& Militky, J. (2016). A new method and apparatus for evaluating the electromagnetic shielding effectiveness of textiles. Textile Research Journal, 86(1), 44-56.

Stefan, B., Tomasz, R., Iwona, K., Grazyna, M., Edward, R., Lech, S., . . Katarzyna, S. (2009). extile Multi-layer Systems for Protection Against Electromagnetic Radiation. Fibres and Textiles in Eastern Europe, 2(73), 66-71.

Thomassin, J. M., Jerome, C., Pardoen, T., Bailly, C., Huynen, I., \& Detrembleur, C. (2013). Polymer/carbon based composites as electromagnetic interference (EMI) shielding materials. Materials Science and Engineering R Reports, 74(7), $211-232$.

Volski, V., \& Vandenbosch, G. A. (2009). Full-wave electromagnetic modeling of fabrics and composites. Composites Science and Technology, 69(2), 161-168.

Yang, Y., Gupta, M. C., Dubley, K. L., \& Lawrence, R. W. (2005). A Comparative Study of EMI Shielding Properties of Carbon Nanofiber and Multi-Walled Carbon Nanotube Filled Polymer Composites. Journal of Nanoscience and Nanotechnology, 5(6), 927931. 